\title{
RECOMMENDATIONS AND GUIDELINES FOR APPLIED NUTRITION EXPERIMENTS IN RABBITS ${ }^{1}$
}

\author{
Fernández-Carmona J.", Blas E.*, Pascual J.J.*, Maertens L. ${ }^{\dagger}$, \\ Gidenne T. *, Xiccato G. \$, García J. ॠ
}

*Dpt. Ciencia Animal, Universidad Politécnica de Valencia, 46071 Valencia, Spain.

${ }^{\dagger}$ Centre for Agricultural Research, Dpt. Animal Nutrition and Husbandry, 9090 Melle, Belgium.

*Station de Recherches Cunicoles, INRA, BP 5627, 31326 Castanet Tolosan Cedex, France.

${ }^{\S}$ Dpt. Scienze Animali, Università di Padova, 35020 Legnaro (PAdOva), Italy.

`Dpt. Producción Animal, Universidad Politécnica de Madrid, 28040 MADRID, Spain.

\begin{abstract}
Aвstract: The aim of this paper was to draw up a set of recommendations for applied nutrition and feeding trials with rabbits, in relation to certain aspects such as determining the nutritive value of raw materials or diets in growing or reproducing animals, studying digestive physiology and obtaining growth and reproduction parameters. We deal first with animals, size of the sample, housing conditions, diets, handling, measurements, and the data analyses relevant to the design of the experiment are described. Secondly, we give a list of recommended items and include some comments.
\end{abstract}

Key words: rabbit, guidelines, nutrition, growth, reproduction.

\section{INTRODUCTION}

Various papers have been published to harmonize criteria on rabbit meat (BLASCO and Ouhayoun, 1996) or to present an overview of the traits which should be included in experiments on growth and reproduction (BATTAGLin et al., 1992). The International Rabbit Reproduction Group (IRRG, 2005) has recently published

Correspondence: J. Fernández-Carmona

E-mail:jfernandez@dca.upv.es

${ }^{1}$ This paper was compiled within the activities of E.G.R.A.N. - European Group on Rabbit Nutrition.

(http://www.dcam.upv.es/egran/). 
guidelines dealing with experimental reproduction work, where the main characteristics and conditions for experiments with reproductive doe rabbits have been detailed. Concerning feeding experiments, the European Group on Rabbit Nutrition (EGRAN) adopted a common reference method for in vivo determination of apparent diet digestibility (Perez et al., 1995a and b) and also published an article that attempted to harmonise chemical analyses of feeds and faeces for rabbit feeding evaluation (EGRAN, 2001).

In a review of 238 papers on feeding experiments, mainly related to growth and fattening, PAscual et al. (2002) reported that in a great number of assays essential data on experimental conditions are lacking (description and analysis of diets, measures or size of sample). Thus, there appears to be a need for establishing common criteria for designing nutrition and feeding experiments, as well as for explaining the results. The present paper was prepared by a panel of researchers of the EGRAN group at various European meetings (COST Action 848 sponsored by EU, http:// www.dcam.upv.es/cost848/). During the $8^{\text {th }}$ World Rabbit Congress in Mexico (September 2004) this topic was discussed during the Round Table "Guide on research work in rabbit nutrition". This paper is the final report of the panel on this topic.

\section{GENERAL GUIDELINES}

The recommendations deal with feeding/nutrition experiments aiming to evaluate the effects of dietary treatments on different aspects, such as feed nutritive value, digestive physiology, growth, reproductive performance and health status. Most of them may be carried out in commercial farm conditions but preference should be given to a well-controlled experimental facility because of the difficulties of measuring certain traits (i.e. feed intake) or in correctly following the experimental protocol. Special attention should be paid to limiting the number of treatments, avoiding complex protocols and concentrating on essential analyses or measures.

Recorded traits for specific research purposes can be quite diverse, particularly in studies on digestive physiology, which may include aspects on microbiology, immunity 
assays, digesta flow, nitrogen and marker kinetics, and so on. Here, we only intend to mention relevant traits included in normal feeding studies and remark on various aspects which may be useful in designing, writing or refereeing a paper. It is not our aim to establish a definitive set of recommendations, provide retraining or to oblige researchers to apply any particular analysis. The freedom of researchers to plan their study and the independence of referees to evaluate a paper must be respected.

\section{Animals}

Because of the easy availability of improved lines of New Zealand White or commercial hybrids, particularly in Western Europe, preference should be given to using these strains when the experiment deals with "professional" breeding systems. Other breeds or strains can be used as required for specific purposes, or if extensively used in a particular country, but reliable information from organisations such as the Ministry of Agriculture, farming associations or commercial hybrid companies should be included to describe the phenotype of these strains. Since growing rabbits are highly sensitive to diseases, special efforts should be made to see that only healthy animals are included throughout the experiment. The health status of the animals should be strictly controlled, both to ensure animal welfare and to avoid bias in the results.

An experimental design that includes only one or two main objectives is advisable in order to obtain a clear interpretation of the results. A control group, which follows the same procedures as the experimental group, is strongly recommended. When the design of the experiment is unavoidably complex, a figure or scheme can be useful to clearly describe it.

If the fattening period is short and ends before 11 weeks of age, it is not necessary to take into account the sex of the animals. However, even at this age some effects of gender can be observed in carcass traits, in particular on the dressing percentage, which is about $0.5 \%$ lower in females than in males (LAMBERTINI et al., 1990; PARIGI BINI et al., 1992; TROCINo et al., 2003). Replacing or removing animals is not generally permitted during the procedure. In all cases, the size of the sample to which the 
results refer must be reported. The number of animals and samples analysed should be reported in all tables.

Least squares analysis can usually provide unbiased estimates of treatment effects, but does have certain limitations. If there are numerous "missing data" as consequence of removed or dead animals, the statistical analyses should not be performed and the trial should be repeated.

\section{Size of the sample}

The number of animals in each experimental group (replicates) depends on the variability of the trait studied, the expected difference, and the level of significance requested.

Table 1 shows the coefficients of variation of different production traits. Many of them have a high variability and therefore a large number of observations is necessary to detect significant differences.

The most important, and the most often neglected step in designing an experiment, is the calculation of the number of replicates needed to give a reliable outcome. This topic has been emphasised by some groups in recent years, who subjected the minimum number of animals to experimental conditions, and also due to the high cost of replicates. The number of replicates ( $\mathrm{n}$ ) necessary per treatment to detect a significant difference between two different treatments can easily be calculated from the least significant difference formula: $\mathrm{n}>2 t^{2} \mathrm{~s}^{2} / \mathrm{d}^{2}$; where: $t=$ Student's $t$ for a chosen probability and degree of freedom appropriate to the error variance; $\mathrm{s}^{2}=$ the error variance (the variability of our experimental data); and $d=$ relevant difference (the size of the difference that we wish to detect). This equation is usually simplified to $\mathrm{n}>8(\mathrm{CV})^{2} / \mathrm{d}^{2}$, (where $\mathrm{CV}$, coefficient of variability, and $\mathrm{d}$ are expressed as a percentage value), since the value of $t$ for $P=0.05$ varies from 2.09 to 2.00 for 20 to 60 degrees of freedom. Both $\mathrm{CV}$ and d values may be estimated from the literature, previous experience and analogous experiments. There are excellent reviews that can be consulted for further information about these questions (MAROUNEK et al., 1999; GarCía et al., 2001). 
Taking into account that the variability of growth and reproductive traits may fluctuate widely between different experiments (see Table 1), it is difficult to give a general recommendation on the size of a sample. Also, the difference regarded as relevant may itself vary, according to the aim of the experiment in question. For example, if the $\mathrm{CV}$ for average daily gain is $10 \%$ (mean $=40 \mathrm{~g}$ /day, residual standard deviation $=4 \mathrm{~g}$ /day) and we wish to detect a difference between means of $5 \%$ ( $2 \mathrm{~g} /$ day), the minimum number of replicates per experimental group should be 32 . In the absence of more precise information on the variability of traits and measurements,

Table 1: Coefficient of variation $(\mathrm{CV})$ for some productive traits and minimum number of replicates recommended.

\begin{tabular}{|c|c|c|}
\hline Parameter & CV $(\%)$ & Minimum replicates (No.) \\
\hline Chemical analyses ${ }^{1}$ & & $2-3^{10}$ \\
\hline Dry matter & $0.5(0.6)$ & \\
\hline Ash & $2.2(2.9)$ & \\
\hline Crude Protein & $5.0(6.6)$ & \\
\hline Ether Extract & $16.6(22.7)$ & \\
\hline Fibre Fractions & $4.0-5.0(1.9-2.9)$ & \\
\hline Acid Detergent Lignin & $11.1(5.7)$ & \\
\hline Gross Energy & $0.6(1.5)$ & \\
\hline Apparent digestibility coefficient $(\%)^{2}$ & & $10^{11}$ \\
\hline Dry matter & 1.1 & \\
\hline Gross Energy & 1.6 & \\
\hline Crude Protein & 2.7 & \\
\hline Fibre fractions & $21-34$ & \\
\hline Growth trials & & 30 \\
\hline Average daily gain (g/day) & $17[1-50]^{3}$ & \\
\hline Food intake & $11[1-38]^{3}$ & \\
\hline Cold Carcass dressing (\%) & $3.6^{4}$ & \\
\hline Reproducing doe trials & & 30 \\
\hline \multirow[t]{2}{*}{ Food intake (g DM/d): } & $22[14-35]^{5}$ & \\
\hline & $14[5-26]^{6}$ & \\
\hline Litter weight at $28 \mathrm{~d}(\mathrm{~g})$ & $19[2-39]^{7}$ & \\
\hline Milk output (g/d) & $17[9-35]^{8}$ & \\
\hline Litter size (no., alive) & $20-25^{9}$ & \\
\hline Litter size at weaning & $20-25^{9}$ & \\
\hline
\end{tabular}

[Values in square brackets shows the $\mathrm{CV}$ values range observed]. ${ }^{1}$ Values for feeds (values for faeces are in brackets). Fibre fractions include Crude Fibre, Acid Detergent Fibre and Neutral Detergent Fibre, EGRAN (2001). ${ }^{2}$ Fibre fractions include values for Crude Fibre (22\%), Acid Detergent Fibre (34\%) and Neutral Detergent Fibre (21\%); CV\% value for Acid detergent lignin was $115 \%$, PEREZ et al. (1995b). ${ }^{3}$ to ${ }^{8}$ Values deduced from the following number of experiments: ${ }^{3} 440,{ }^{4} 170,{ }^{5} 6,{ }^{6} 13,{ }^{7} 20$, and ${ }^{8} 9$ experiments. ${ }^{9}$ IRRG (2005). ${ }^{10}$ Three replicates for feed samples and two replicates for faecal samples in digestibility trials, EGRAN (2001). ${ }^{11}$ PEREZ et al. (1995b). 
a minimum number of 30-40 animals per experimental group should be foreseen in order to obtain reliable results, both for growth and reproductive performance and the main carcass characteristics.

Equalising litters or groups generally has the effect of notably reducing the coefficient of variation, and hence the number of replicates required. As a general rule, very few treatments should be tested when the number of replicates is not high. It is always better to reach sound and significant conclusions on a limited scope than to try to examine the broad aspect of a question, obtaining unreliable results.

These recommendations were designed to find the significant relevant differences in the most important parameters controlling growth (feed intake, daily gain and conversion rate) and reproductive trials (live weight changes, feed intake, milk yield...). However, it must be emphasised that this number of replicates may not be appropriate for certain parameters frequently controlled in this type of trial, such as mortality during the growing period or litter size at birth. In any case, the number of replicates depends on the animal variability in the experimental facility. For an adequate experimental design, the number of observations necessary in each group can be obtained from the recommendations given above.

Table 1 also shows the recommended minimum number of replicates per treatment, according to the suggestions of EGRAN (2001) for chemical analysis, and those of Perez et al. (1995a and b) for digestibility trials.

\section{Establishment of the group}

Theoretically, animals should be randomly allocated to treatments. However, local controls may impose some restrictions to this rule, for example to take into account known (or supposed) initial differences in the experimental material. Therefore, rabbits must be distributed with similar criteria between the different experimental treatments at the beginning of the trial, with similar age, weight, physiological status or performance in the case of females, and pre-experimental treatments. 
Weanlings should be distributed homogeneously between the different treatments, taking into account the origin of the litter. Frequent changing of the rabbits in a cage gives irregular results. When forming a new group of animals in the same space or cage, or even when adding or removing individuals, it has to be remembered that a new dominance order will be established after some days and may influence the results during that period.

\section{Environmental conditions}

The different experimental groups should be housed in the same section of the building, or be homogeneously distributed between the different experimental rooms and cage rows. The light-dark cycle should be reported for outdoors, and programming is recommended for indoor trials. Other housing characteristics should also be determined or at least clearly described (temperature, ventilation and characteristics of cages).

\section{Growth and fattening}

Individual caging has the advantage that feed intake can be measured exactly. When animals are housed in collective cages, the experimental unit should also be the cage for daily weight increases and not the individual animal, since neither feed intake nor conversion index can be determined individually. In this case, correction of the results due to the death of one or more animals may present problems. It is recommended to record feed intake on a weekly basis, registering the dates of deaths in order to determine the number of rations offered. The duration of a fattening experiment, although varying according the objectives, should last most, if not all, of the period from weaning to slaughter.

\section{Reproducing does}

The most important questions about groups, reproductive rate and insemination are discussed in the paper IRRG (2005). The convenience of equalizing litters at birth and throughout lactation, adding kits weekly, should be considered. This standardisation removes the effect of litter size on milk output and the body condition of the doe, and reduces the coefficient of variation of most results. 
The number of animals may be greater than that foreseen before starting the experiment, since the differences between the imposed and the actual re-mating may increase the final number of the different groups to be compared. Also, in feeding experiments the effect of nutrition is affected by the variation in body condition throughout consecutive cycles. This means that a relatively long term experiment should be planned, if the variations in body condition are not measured or estimated (comparative slaughter, ultrasound technique).

\section{Mortality and morbidity}

During lactation, mortality should be expressed both as a percentage of the initial number of young rabbits (after standardisation) and as the total number of lost litters. It is strongly recommended to record litter size and weight at 21 days post partum, since they are strongly dependent on maternal milk production. Number of young weaned rabbits, weaning age and weaning weight are important traits in judging general productivity.

In Europe, the incidence of epizootic rabbit enterocolitis (ERE) has meant increased interest in measuring morbidity during growth. According to BENNEGADI et al. (2001) this consists of an external examination to detect: a) light, acute or terminal diarrhoea; b) caecal blockage; c) mucus in faeces; d) abnormal caecotrophy (more than 3 days with the presence of significant soft faeces); e) incidence of digestive problems; in addition, f) animals not included in the previous categories, but with an abnormally low growth rate during a period of one week, i.e. under "mean \pm 2 SD" within a group of at least 30 rabbits. From the above definitions a sanitary risk index $(\mathrm{SRI} \%=$ mortality $\%+$ morbidity $\%)$ can be estimated.

\section{Productivity}

Productivity at a given moment or period, which should be specified (birth, weaning, end of fattening period), is an efficiency criterion with practical and nutritional significance which takes into account fertility, litter size and litter weight at the selected time. For example, global productivity at weaning is the ratio between the weight of weaned rabbits and the number of mated/inseminated does. This productivity index is a useful tool for determining the usefulness of a treatment (or a 
method) as it includes not only reproductive performance but also growth and viability of young rabbits.

\section{Feeding system}

The ingredients included in diets should be listed in a table, with some indications as to their quality (i.e. protein and fibre concentrations). Special importance should be given to the main ingredients and those that vary substantially in quality (these are generally forages in both cases). The normal English names of raw materials should be used. The Tables of Composition published by INRA (2002) give a detailed list of feedstuffs with a brief description of each. In the case of unusual or exotic raw materials not clearly identified by the common name, the specific Latin name should be given.

Besides the assessment of growth, a relevant objective of applied feeding experiments is to determine the voluntary feed intake. For this purpose the quantity of diets offered and refused, raw materials or mixtures should be calculated (on a dry matter basis in case of mixtures containing both dried and fresh raw materials). Voluntary feed intake is strongly influenced by the physical form and energy value of the diet. It is therefore necessary to clearly define the form in which the diet or mixtures are offered and also any processes to which they may have been subjected.

Changes in composition and distribution during the experimental period should be minimal and attention should be drawn to the use of only one batch of feedstuffs, or at least one batch of the main forage included in the diet. Although reproducing rabbits are generally fed ad libitum, a fixed feeding system may be required during the different reproduction phases. Since rabbits eat dry food, free access to drinking water is necessary, preferably with an automatic system.

\section{Feed analyses}

Reliable analytical methods are essential for interpreting data in nutrition research. It is extremely important to determine in vivo the value of the digestible energy of the experimental diets (or feeds). When in vivo measurement is not possible, the nutritive value should be calculated, specifying the method or formula used. Recent 
tables of feed ingredients, either from the EGRAN group (MAERTENs et al., 2002) or from INRA (2002), are valuable for this purpose. Some of the nutrient fractions should be analysed, at least the protein and fibre, and any others that could affect the quality of the diet. A recent report (Uden et al., 2005) discusses the development of the detergent system of dietary fibre fraction analysis and suggests the use of a new terminology.

The description of the feeds should also report any additives (such as premix, vitamins, minerals, probiotics or prebiotics) or drugs (i.e. antibiotics, coccidiostatics). In general, details should be given of all additives, reporting the commercial name, manufacturer and concentration of the active molecule.

\section{Statistical analyses}

The following recommendations, which are mostly an extract from those given for reproductive indexes by IRRG (2005) may serve as a guide:

1. All factors should be expressed simultaneously in the statistical model.

2. Before testing an effect or an interaction, it should be checked that each basic cell comprises a minimum of 10 observations. If not, cells should be grouped when there is biological significance. If the first order interactions are non significant, they should be excluded from the model.

3. Litter size can be analysed as a continuous variable and mortality can be studied by analysing litter size at any stage after birth, introducing birth litter size as a covariate in the model.

4. For non-continuous classified data, such as number of dead or morbid animals, the statistical analysis should use an appropriate procedure to compare treatments, for instance the Chi-square test. The CATMOD procedure (see SAS/STAT user's guide, http://v8doc.sas.com/sashtml/) can be used for a more complex design (more than two levels within a treatment, or for bi-factorial models).

5. Mean values indicated for a particular factor should be the least square means given with standard error and the number of recordings.

6. If using the specific authors' guide of the scientific journal, the statistical significance of any difference is indicated "NS" (non significant) when $P>0.05$, 
* when $P \leq 0.05$, ** when $P \leq 0.01$ and *** when $P \leq 0.001$. However, it is recommended to present the exact probability of each trait (instead of level only).

Models with repeated measures (variables measured in the course of several reproductive cycles or growing periods) are a special case. This type of model cannot be analysed by the usual ANOVA procedure since two of the analysis of variance assumptions are not met in most cases: homogeneous variance throughout the period (variance of the trait usually changes with time) and the independence of different estimates (adjacent measurements are likely to be correlated and are thus not independent estimates of the performance of the animal).

Therefore, in the case of repeated data more complex models should be considered (for example: using a mixed linear model to take into account more complex structures of variance-covariance, taking into account correlations between data or relationships between individuals...). A good description of the treatment of problems that can arise with repeated measures can be found in CROWDER and HAND (1990) and LitTell et al. (1998).

\section{Commercial studies}

In general, commercial studies are beyond the objective of biological experiments and should not be included in this specific context. Some considerations concerning this aspect may be given in a paper, but the market prices of labour, services, feedstuffs, etc. vary widely from one country to another and change continuously. Thus, in general, commercial information seems to be useful only for a limited local diffusion.

\section{FINAL CONSIDERATIONS}

The conditions relating to animal experimentation must meet the basic principles of animal welfare. Many international institutions have published the current legislation and recommendations on principles of ethical care, guidelines and codes of practice 
for animals used in experimental works, among others the COUNCIL FOR THE International Organizations of Medical Sciences (1985) and the European Union (2003). Experiments should take into account the recommendations or legislation on the use and care of experimental animals, and also the attitude of consumers to welfare and quality aspects. Animal experimentation involving cruelty is not acceptable to most Editors of Animal Science Journals.

A list of relevant items with some comments are presented in Appendixes 1 and 2. These items are generally easy to perform and obviously, depending on the objective of the work, some of those cited in the list may be unnecessary. Some analyses may not be carried out due to lack of the appropriate technical facilities, but it is important to emphasise that many others, although easily performed, are often simply forgotten.

Acknowledgements: This study was partly supported by the EUROPEAn COMMISSION (ERAFE program and the COST 848 Action).

\section{REFERENCES}

Battaglini M., Chiericato G.M., Masoero G., Parigi-Bini R., Xiccato G. 1992. Materiale da utilizzare e metodologie da seguire nelle prove di accrescimento e di riproduzione del conoglio. Zootecnica e Nutrizione Animale, 18: 323-327. Bennegadi N., Gidenne T., Licois L. 2001. Impact of fibre deficiency and sanitary status on non-specific enteropathy of the growing rabbit. Animal Research, 50: $401-413$.

Blasco A., Ouhayoun J. 1996. Harmonization of criteria and terminology in rabbit meat research. Revised proposal. World Rabbit Sci., 4: 93-99.

Council For the International Organizations of Medical Sciences 1985. International Guiding Principles for Biomedical Research Involving Animals. Executive Secretary C.I.O.M.S., Geneva, Switzerland. www.cioms.ch/ frame_1985_texts_of_guide-lines.htm.

Crowder M.J., Hand D.J. 1990. Analysis of Repeated Measures. Chapman \& Hall, London.

EGRAN (European Group on Rabbit Nutrition) 2001. Technical Note: Attempts to harmonize chemical analyses of feeds and faeces for rabbit feeding evaluation. World Rabbit Sci., 9: 57-64.

EUROPEAN UNION 2003. Protection of animals used for experimental purposes. Council Directive 86/609/EEC of 24 November 1986, amended 16.9.2003.

García J., Nicodemus N., Carabaño R., Villamide M.J., De Blas C. 2001. Determination of the number of replicates required to detect a significant difference between two means in rabbit traits. World Rabbit Sci., 9: 27-32. 
Gidenne T., Lapanouse A., Fortun-Lamothe L. 2004. Feeding strategy for the early weaned rabbit: interest of a high energy and protein starter diet on growth and health status. In Proc.: $8^{\text {th }}$ World Rabbit Congress, Puebla, México. pp. 852860 .

INRA. 2002. Tables de Composition et de valeur nutritive des matières premières destinées aux animaux d'elevage. In: SAUVANT D., PéreZ J.M., TRAN G. (coord). INRA Editions., Paris.

IRRG (International RabBit Reproduction Group) 2005. Recommendations and guidelines for applied reproduction trials with rabbit does. World Rabbit Sci., 13: 147-164.

Lambertini L., Benassi M.C., Zaghini G. 1990. Effetto di sesso e peso sulle caratteristiche qualitative della carcassa di coniglio. Rivista di Coniglicoltura 27: 33-39.

Littell R.C., Henry P.R., Ammerman C.B. 1998. Statistical analysis of repeated measures data using SAS procedures. J. Anim. Sci., 76: 1216-1231.

Maertens L., Pérez J.M., Villamide M., Cervera C., Gidenne T., Xiccato G. 2002. Nutritive values of raw materials for rabbits: EGRAN Tables 2002. World Rabbit Sci., 10: 157-166.

Marounek M., Skrivanova V., Vozna O. 1999. Variability of caecal parameters in rabbits. Cahiers Options Méditerránees, 41: 81-84.

Parigi Bini R., Xiccato G., Cinetto M., Dalle Zotte A. 1992. Effetto dell'età, del peso di macellazione e del sesso sulla qualità della carcassa e della carne cunicola. 1. Rilievi di macellazione e qualità della carcassa. Zootecnica Nutrizione Animale, 18: 157-172.

Pascual J.J., Cervera C., Fernández-Carmona J. 2002. Revisión de trabajos de investigación sobre conejos. In Proc.: Segundo Congreso Internacional de las Américas La Habana, Cuba. N17, pp.130-132.

Perez J.M., Lebas F., Gidenne T., Maertens L., Xiccato G., Parigi-Bini R., Dalle Zotte A., Cossu M.E., Carazzolo A., Villamide M.J., Carabaño R., Fraga M.J., Ramos M.A., Cervera C., Blas E., Fernández J., Falcao e Cunha L., Bengala Freire J. 1995a. European reference method for in vivo determination of diet digestibility in rabbits. World Rabbit Sci., 3: 41-43.

Perez J.M., Cervera C., Falcao e Cunha L., Maertens L., Villamide M.J., Xiccato G. 1995b. European ring -test on in vivo determination of digestibility in rabbits. World Rabbit Sci., 3: 171-178.

Trocino A., Xiccato G., Queaque P.I., Sartori A. 2003. Effect of transport duration and gender on rabbit carcass and meat quality. World Rabbit Sci., 11: 32-43.

Uden P., Robinson P.H., Wiseman J. 2005. Use of detergent system terminology and criteria for submission of manuscripts on new or revised, analytical methods as well as descriptive information on feed analysis and/or variability. Animal Feed Science and Technology, 118: 181-186. 


\section{APPENDIX 1}

Table 1: List of traits and analyses and their level of importance according to the experimental purpose.

Experiments especially connected to

Digestive physiology Nutritive value Growth Reproduction

A. MATERIAL AND METHODS

\section{A.1. Farm/Building}

Location (farm, region, country)

Time (year-months, season)

Ambient open air/building

control of ambient

mean temperature

relative humidity

light/darkness cycle

\section{A.2. Animals}

Number

Breed/Commercial cross

Sex

Age (initial and final)

Weight (initial and final)

Allocation (individual or group)

Cage (dimensions or density)

Digestive method for digestibility

physiology method for isolate organs or tissuses analytical methods

Reproduction cycles /parities (No. and order)

farm system

imposed rhythm of reproduction

mating system /insemination

litter size (regulation)

litter size (method for replacement)

milk (method of measurement)

weaning age/weaning weight

Growth/meat age and weight (initial and final) for production each fattening period

frequency for recording live weight and feed intake

method of slaughtering

hours fasting prior slaughtering

number of slaughtered animals

sex of slaughtered animals

age of slaughtered animals

live weight of slaughtered animals

kidney fat

Health

definition

problems
$* * *$

$* *$

$* * *$

$* *$

$* *$

$*$

$* * *$

$* * *$

$* * *$

$* * *$

$* * *$

$* * *$

$*$

$* *$

$* * *$

$* * *$

$* * *$

$* * *$

$*$

$* * *$

$* * *$

$* * *$

$* * *$

$* * *$

$* * *$

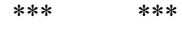

$* * *$

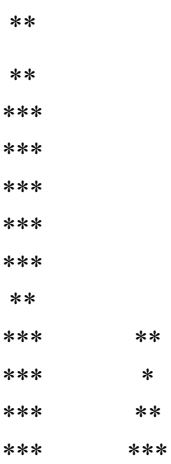

$* * *$ 
Continuation of Table 1.

Experiments especially connected to

Digestive physiology Nutritive value Growth Reproduction

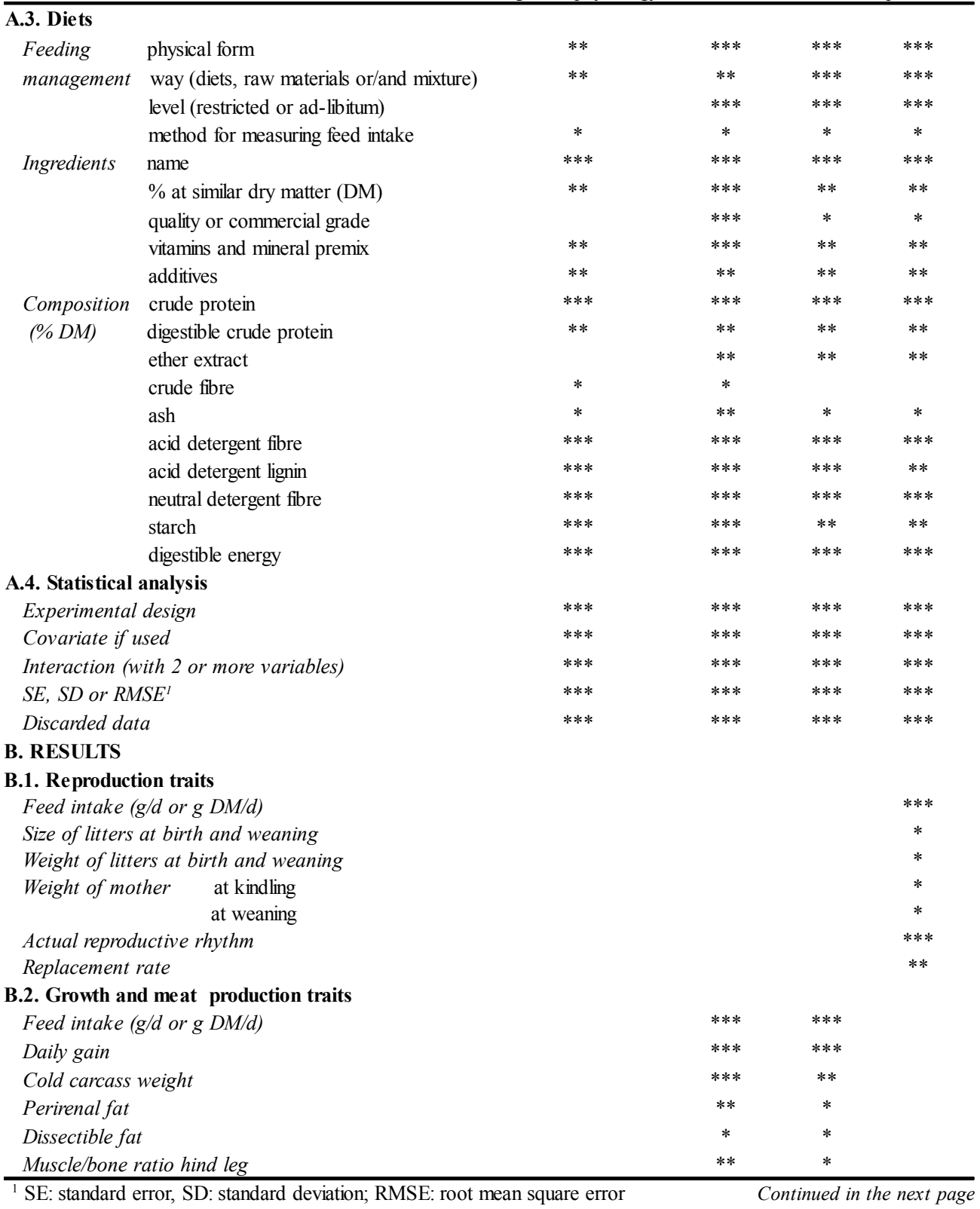


Continuation of Table 1.

Experiments especially connected to

$\overline{\text { Digestive physiology Nutritive value Growth Reproduction }}$

\begin{tabular}{|c|c|c|c|c|c|}
\hline \multicolumn{6}{|c|}{ B.3. Digestive physiology traits } \\
\hline \multicolumn{2}{|c|}{ Total apparent digestibility } & $* * *$ & $* * *$ & $*$ & * \\
\hline \multicolumn{2}{|c|}{ Ileal digestibility } & * & & & \\
\hline \multirow[t]{2}{*}{ Total digestive tube weight } & be weight & $*$ & & & \\
\hline & filled & $*$ & & & \\
\hline \multirow[t]{2}{*}{ Caecum weigh } & empty & $*$ & & & \\
\hline & filled & $*$ & & & \\
\hline \multicolumn{2}{|l|}{ Mucosa histology } & * & & & \\
\hline \multirow[t]{2}{*}{ Health problems } & number of dead and discarded animals & $* * *$ & $* * *$ & $* * *$ & $* * *$ \\
\hline & main causes of mortality and morbidity & $* *$ & $* *$ & $* * *$ & $* * *$ \\
\hline
\end{tabular}

*** strictly required; ** highly recommended; * recommended. 


\section{APPENDIX 2}

\section{COMMENTS ON THE LIST OF TRAITS REPORTED IN APPENDIX 1}

These include the traits which should be specified in:

\section{Material and Methods}

Many traits are required to correctly define the work needed for the experiment to be repeated (a strict requirement for any scientific work). Other traits are considered necessary to be determined in a feeding or nutrition experiment. It is always necessary to specify the method and frequency of sampling and analyses.

Scheme: This is recommended when the design of the experiment is complex (see the Figure 1).

\section{Results}

All measurements considered and described in Material \& Methods should be given and/or commented here. Besides those cited in the list, any others linked to the objectives of the work should be included.

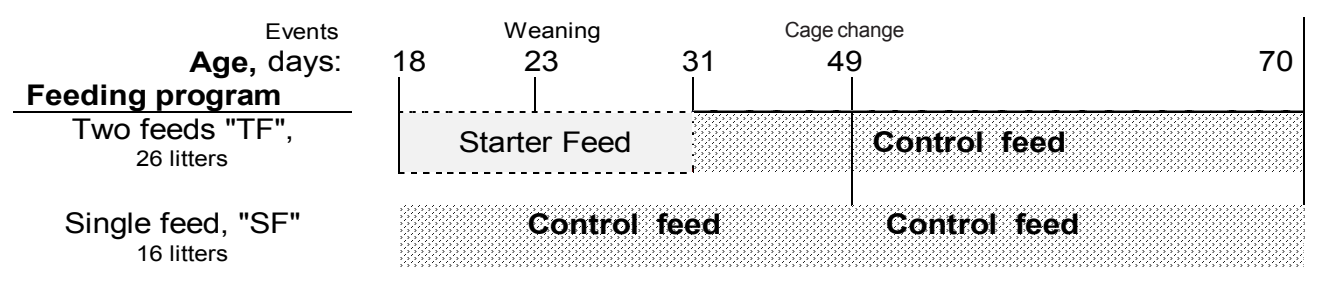

Figure 1: Example of a explanatory figure for experimental design (GuidenNE et al., 2004). 


\section{References}

It is recommended not to cite, if possible, papers with a limited circulation or those not easily obtainable. Scientific Journals are preferable Scientific Meetings. Commercial papers should be cited in an appropriate context and should be easily consulted.

\section{Details of items}

Location: at least city or region.

Time when the experiment took place: initial and final month.

Farm system: (individual or group management) when this may affect the results. Size of sample:

Indicate the size of the sample for the different trials/items of the work. Establish a minimum size per treatment (i.e. 8 rabbits per digestibility and 30 per fattening trial) below which results cannot be considered, to be reliable.

Reproduction:

- Imposed rhythm of reproduction.

- Days from parturition to mating/insemination.

- Days from negative test of pregnancy to $2^{\text {nd }}$ and following mating/insemination (evaluate the deviation between the theoretical/imposed and the actual rhythm of reproduction).

- Mating/insemination system.

- Does/bucks ratio.

- Number of attempts/buck/week.

- Insemination / hormonal treatments.

- Number of spermatozoids/dose.

- Test of pregnancy.

Equalisation of litters:

- Frequency of inspections.

- Origin of replaces (same farm/same treatment; age and weight of replaces).

- Number and moment at which it is equalized (at birth, for 1 week, for the whole lactation...).

Milk measure: frequency and method (mother or litter weight). 
Reasons for discarding animals; i.e.: no pregnancy, milk depletion, abortions, illness... Correction for:

This refers to any data so far analysed. The typical case is feed intake of a group where some individuals are dead or show some kind of morbidity, the composition of a part of the milk output, lack of data or only available for part of a period. At least some calculation of the maximum error involved should be given. If necessary, discard all data relating to a group.

Slaughter:

- Age and weight can be different to final fattening or trial weight, if there is a delay in slaughtering.

- Hours of fasting are related to carcass dressing percentage.

- Method of slaughtering is important because of the legal and welfare considerations.

- Definition of carcass and cuts.

- For dietary energy value determination, it is recommended to measure dissectible or kidney fat.

Diets:

- Define as commercial when it comes from a manufacturer.

- Report the physical form of diets (mash, wafers or pellets), raw materials (whole, cut, grinding or meal) and mixture of both.

- Give some indication of the quality of raw materials, at least that of the main forage and by-products included when there can be a substantial variation in composition (fresh, silage or hay forage; wheat, barley, rice or maize byproducts). This can be their fibre or protein content, commercial name. The names should follow UK, USA, EU or other official accessible regulations. - Include method for digestibility trial and analyses. Always specify whether the data are experimental or calculated values.

- Better to give feed intake on a dry matter basis or considering the error due to dry matter analysis performed at a different time than the ingestion time. In case of possible feed selection (simultaneous diets or mixture of diet and ingredients, such as forages), give weight, and composition if possible, of refusals. 
Statistics:

Specify the data analysed so far. It is very important to program an adequate size of sample.

Reasons for discarding data:

A clear reason is an obvious error of sampling or transcription to the file. It is not generally allowed to remove data. In all cases the size of the sample which provided the results should be reported.

Results:

- Do not give tendencies or trends unless the $P$ - value is also given.

- Feed intake: giving this in terms of air dried basis may give some error when several diets are considered, since they will have slightly different percentage dry matter values.

- Specify when feed intake values are/are not separated, for: solid and milk intake in kits, solid intake of mother and litters and intake of forage/raw materials when both are given together (notice that refusals can be very different for both). 